\title{
Platform concepts in bridge construction
}

\author{
Johan Larsson ${ }^{1}$, Thomas Olofsson ${ }^{2}$ and Weizhuo $\mathrm{Lu}^{3}$
}

${ }^{1}$ Luleå University of Technology, Department of Civil, Environmental and Natural Resources Engineering, SE-971 87 Luleå, Sweden; PH (+46) 920-492263; email: Johan.p.larsson@ltu.se

${ }^{2}$ Luleå University of Technology, Department of Civil, Environmental and Natural Resources Engineering, SE-971 87 Luleå, Sweden; PH (+46) 920-493662; email: Thomas.olofsson@ltu.se

${ }^{3}$ Luleå University of Technology, Department of Civil, Environmental and Natural Resources Engineering, SE-971 87 Luleå, Sweden; PH (+46) 920-492866; email: Weizhuo.lu@ltu.se

\begin{abstract}
Improving productivity and innovation is a central challenge in all industries, but particularly in construction where improvements have been slow. The Swedish Transportation Administration, the largest public client in Sweden, has launched a research and innovation program to increase productivity by foster an industrial approach and identify ways to increase the standardization of products and processes. The use of customizable platforms in bridge construction is in this paper explored as a tool for increasing the standardization. Especially the connection between the product and process platforms is exemplified using a developed bridge concept by a Swedish contractor. The development of modular platforms needs to consider which components and processes that can be specified (standardized) in advance and which that needs to be uniquely adapted to the specific project. Also, the encapsulation of knowledge in standardized design and construction modules in supporting platforms and configuration tools turn tacit personal know-how into formal explicit knowledge that can be managed and continuously improved by the construction company.
\end{abstract}

\section{INTRODUCTION}

Construction is traditionally an engineer-to-order (ETO) sector where unique, one-off products are designed for specific projects (Lopez and Love, 2012). ETO is characterized by a completely customized supply chain where clients enter early in the engineering phase (Gosling and Naim, 2009). Gibb (2001) stated that construction has always struggle to balance between uniformity and variation, between maximum standardization and flexibility and that construction companies taking standardization seriously has to resolve this balance in order to gain increased productivity and maximum outcome.

Previous research has found that the increase in productivity of the construction industry are slow, especially in the infrastructure sector where many 
projects suffer from cost and schedule overruns (Flyvbjerg et al., 2004; Minchin et al., 2011). Therefore largest public client, the Swedish Transport Administration responsible for the transport system in Sweden, has launched a research and innovation program to increase the productivity of the infrastructure sector by supporting a more industrialized development of products and processes in the industry, (Larsson et al. 2013).

A way to increase industrialization is to move from an ETO strategy towards mass customization, (Haug et al., 2009). The developments of platforms from which a stream of derivative product and processes can be configured have been the mass customization industry strategy to increase flexibility whereas keeping the mass production advantages of productivity and economy of scale (Meyer and Lehnerd, 1997). These platforms should be developed on the basis of modules to fit customers' needs of the target market segment (Hvam et. al., 2008).

The aim of this paper is to investigate how a platform can be defined to support the construction of industrialized bridge concepts. The result is based on a case study of an industrialized bridge concept with a clear product focus. The platform consists today of a highly standardized bridge with a traditional craft based construction process. Suggestions for how the platform can be used and updated in a continuously improvement process from project to project is based on the proposed framework for platforms in ETO construction companies.

\section{PLATFORMS IN CONSTRUCTION}

Robertson and Ulrich (1998) present a strategy for the development of platforms, based on observations of the car industry. The proposed platform is based on four assets shared by a family of products. The assets involve components, processes, knowledge and people and relationships. Components are the physical building blocks used when designing a product and the related tools with manufacturing fixtures. The architecture of a platform product consists of: a modular architecture, defined module interfaces and standards that provide design rules to which the modules of the product family must conform to (Baldwin and Clark, 2000). Miller and Elgård (1998) define a module as an "essential and self-contained functional unit relative to the product of which it is part of. The module has, relative to a system definition, standardized interfaces and interactions that allow composition of products by combination". Building Information Modelling (BIM) can in the product asset function as support for generating or configuring components within a platform based on modules, (Jensen et al., 2012; Jensen et al., 2013).

To produce customized products efficiently, knowledge about production processes are gathered and refined to form the process asset of a platform. Process assets have a generic structure from which variations in diverse products and processes can be differentiated (Jiao et al., 2003). The more common parts and processes that are involved in a platform, the less flexible it becomes. By moving client order decoupling point forward, downstream the design process, the need of knowledge of clients' requirements and preferences increases (Robertson and Ulrich, 1998). According to Styhre and Gluch (2010), the knowledge asset is a mechanism

for bridging between the stocks and flows of knowledge in construction organizations 
by integrating know-how and experience in activities. Knowledge sharing is a complex process and is according to Styhre and Gluch (2010) practiced in traditional construction companies mostly by local networks and oral communication.

People and relationship assets regards internal teams working with the platform as well as all relationships with other companies in the supply chain, some closer coupled to the platform than others (Green et al., 2005). Meyer and Lehnerd (1997) supported the idea that the platform consists not only of physical parts, but also of process technologies and organizational capabilities. A modular platform is according to Meyer and Lehnerd (1997) used to create variants through configuration of existing modules. The platform assets together with input of unique project requirements are then used in different projects to increase efficiently of delivering the product. The outputs from completed projects can then be used to update the platform continuously by, e.g. experience feedback from project to project.

Jansson et al. (2013) proposed a model for platform use for organizations in an ETO construction supply chain. The proposed model is a combination based on the four platform assets defined by Robertson and Ulrich (1998) and Meyer and Lehnerd (1997) definition of platform thinking. The model explains the interactions between projects, the platform, the support methods and experience feedback. The support methods are of special importance since everything in the design cannot be predefined or configured in an ETO construction project, (Jansson et al., 2013). To conclude, platforms according to literature, e.g. Jiao et al. (2007); Jansson et al. (2013); Robertson and Ulrich (1998), consist of three main parts: the product, the production process and the supply of people, material and components. The combination of these parts defines the platform necessary to fit into the purpose of creating variety while sustaining economies of scale (Jiao et al., 2007).

\section{STUDIED BRIDGE CONCEPT}

The result is based on a case study, which often is considered the best strategy for exploring problems that require deep contextual understanding (Merriam, 1998). An industrialized bridge concept will exemplify how platforms can be defined and used in ETO construction projects. The performed case study consists of two steps; first by studying support documents from the existing platform, secondly by observing construction work at site and studying construction documents such as drawings, schedules and cost estimates from one project involving the studied bridge concept. The second part of the case study is previously reported and described more thoroughly in Larsson and Simonsson (2012).

The bridge concept consists of semi-prefabricated beam bridge that is developed for fast and easy construction to minimize traffic disruption. The foundation and substructure (wings and plate structure) is on-site constructed whereas the superstructure consists of prefabricated edge beams, beams and slabs which create the formwork for the covering. After the prefabricated parts and the remaining reinforcement are assembled, the concrete cover is casted to create a continuous superstructure, Figure 1. 


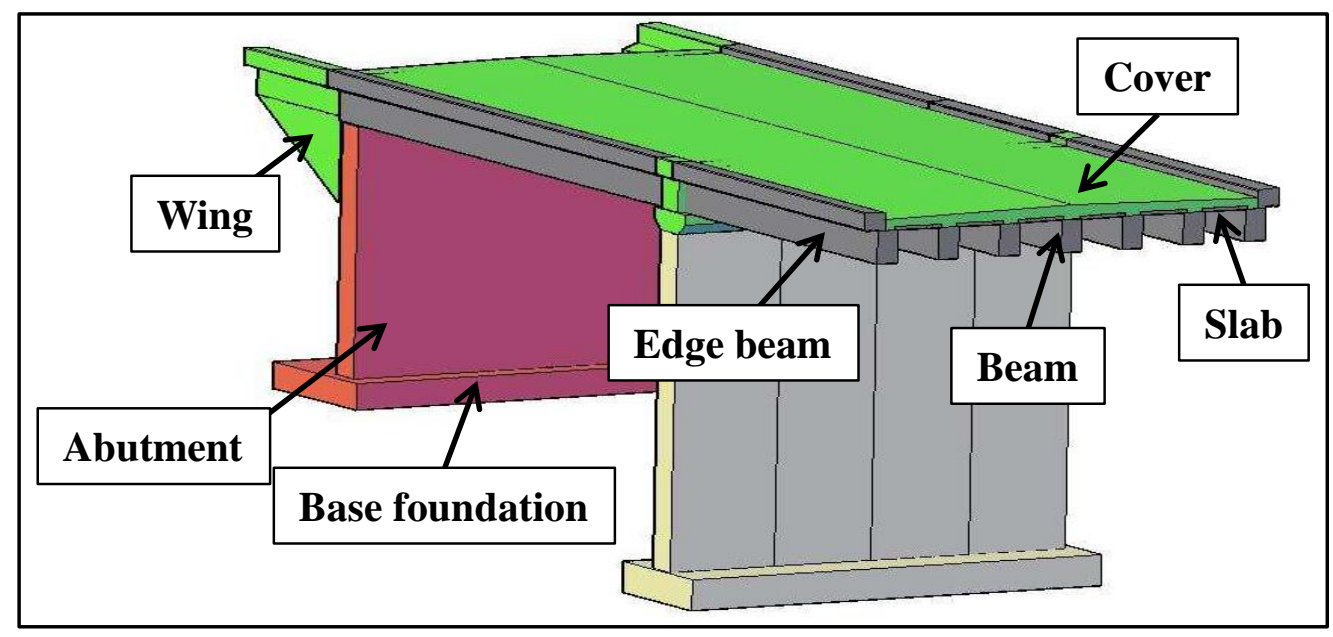

Figure 1. Industrialized bridge concept.

Product architecture. The bridge is physically predefined in the platform with standardized dimensions and shapes in three large modules (foundation, substructure, superstructure) shown in the upper part of Figure 2 . The client is only able to choose among fixed lengths between 12 and 52 meters and different surface structure and coloring of all visible surfaces. There are 12 knowledge documents, mostly drawings and recommendations, connected to the three identified modules within the platform assisting the designer during engineering work.

Production structure. Documentation of the production aspects of the process is absent in the current platform, making the concept very product oriented. Related production documents and work instructions have to be created for each specific project. There is a paragraph about knowledge improvements in the introduction of the platform, but it only consider how the design phase should be performed. These improvements are to be dealt with by the appointed internal management group once a year.

To be able to map the construction process a case study of one specific project was conducted. The production structure is together with the product architecture shown in Figure 2. No activities performed outside the construction site are considered in the case study; hence the purpose was to map the construction process at site to see what activities that are needed to construct the bridge.

Supply chain. Documentation of how the supply chain should work is also absent in the platform, therefore the performed case study also involved this aspect. All reinforcement for the bridge was pre-cut and ready to be mounted into the formwork, before delivered in one batch to the construction site before construction start. The concrete was pumped directly from concrete mixer trucks that arrived to the construction site in a steady flow during the different concreting operations. Prefabricated part was delivered just in time; in the specific assemble order, to be mounted on to the completed plate structure. A crane was parked in a fixed position at the construction site during the whole assembly work of prefabricated components. 


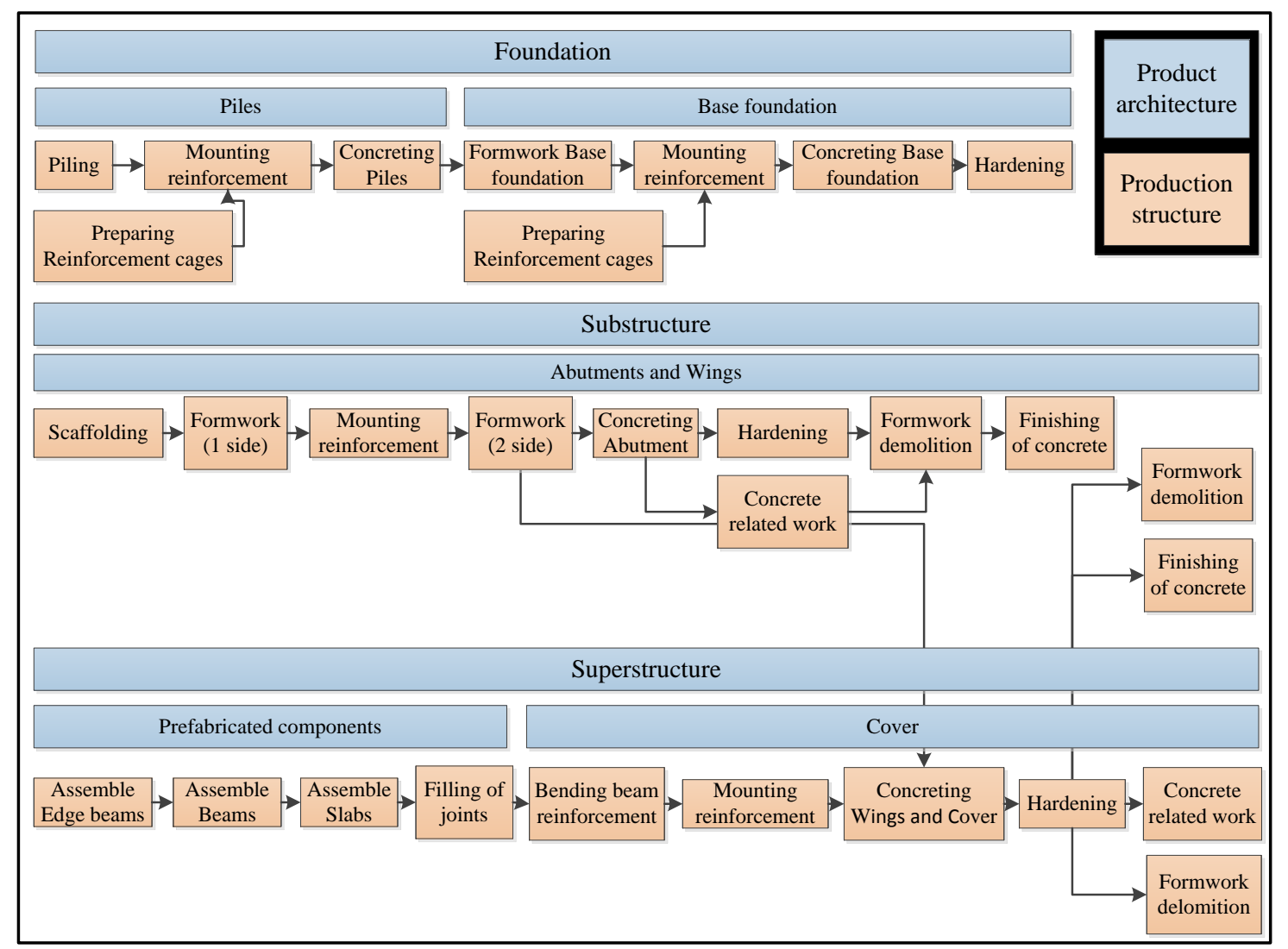

Figure 2. Product architecture and production structure.

\section{PROPOSED FRAMEWORK}

Merging previous literature of platforms with the performed study, a framework on how platforms can interact with and support an ETO construction project is developed and proposed, Figure 3. The different activities and inputs and outputs are partly based on the location-based planning and cost estimation process suggested by Jongeling and Olofsson (2007):

- In the design phase, the Building Information Modelling process (BIM), product architecture can be partly generated or configured from the platform, (Jensen et al., 2012; Jensen et al., 2013). The platform contains predefined component modules that can be configured to fit specific project requirements.

- Next, the BIM model is prepared with work locations for the location-based quantitative take-off. Unique design objects need to be attributed with reference to recipes regarding production methods and resource needs. Objects imported from the platform are already referenced. For highly standardized and parameterized product architectures this step can more or less be automated.

- Cost estimation and scheduling is based on platform recipes including production methods, resource needs and unit costs. For each defined work location; time, costs and needs of resources are estimated and planned. For 
standardized components/modules of the product architecture the use of resources can either be selected to minimize time or costs.

- The work on the construction site is standardized using work instructions from the platform in order to facilitate continuous improvements. Feedback from experience and methods such as value stream mapping can then be used to improve the workflow but also to change the design to improve the buildability of the product, (Larsson and Simonsson, 2012).

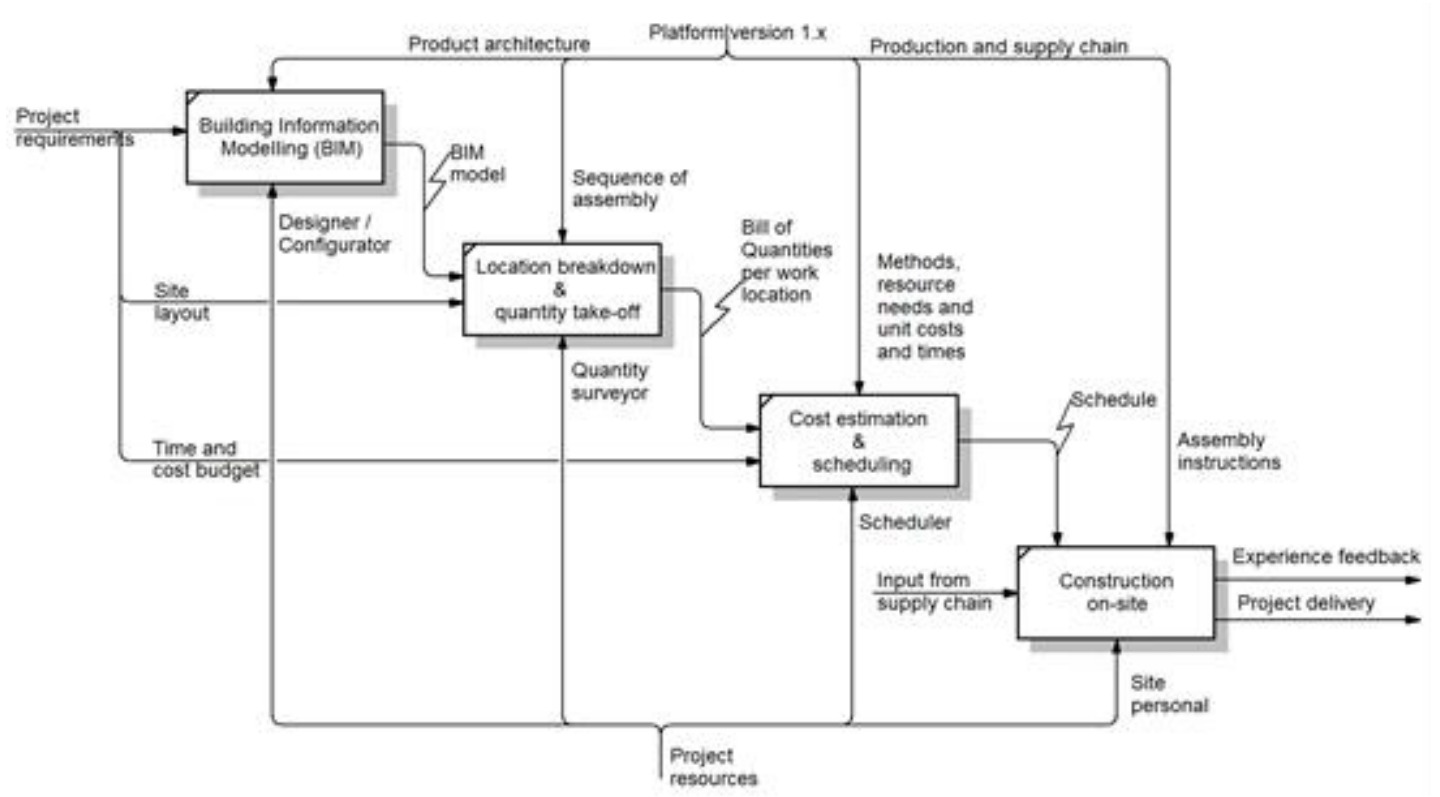

Figure 3. The use of platform technology in construction projects.

\section{DISCUSSION AND CONCLUSIONS}

Although the studied bridge product architecture is highly standardized in three main modules the possibility of configuration by parameterization, e.g. using the width and length of the bridge as governing parameters, has not been practiced in engineering design process. Instead traditional 2D design tools and quantity take-off based on 2D drawings was used. The possibility of pre-manufacturing has been utilized in the assembly of the superstructure. Still more can be done to speed-up the on-site construction of the substructure, e.g. using pre-manufactured formwork system. Also, the lack of a standardized assembly and construction process makes project experiences harder to utilize. Experiences from the project that can be used to improve the buildability design of the product and the realization process in the next project (Larsson and Simonsson, 2012). Based on the ETO organizational model for platforms, (Jansson et al., 2013), and the framework shown in Figure 3, the following proposals on how to establish and develop the platform for the bridge in the case study was delivered to the owner and contractor of the bridge concept: 
- Product architecture. The sub- and superstructure modules should be parameterized using, e.g. required bridge length and width. The buildability of the design of the interface between the prefabricated components and the cover in the superstructure should be improved.

- Customization. The possibilities of developing a design configurator for automation of structural analysis, quantity take-off and schedule generation of parts of the production process should be considered.

- Production structure. Standardized instructions for the assembly and on-site construction operations should be developed to facilitate continuous improvements.

- Supply chain. Prefabrication of more components of the substructure should be considered (e.g. formwork, wings, plate structure)

The contractor has recently started a new research project to develop the bridge platform further taking into account the above suggested proposals. Further research will be performed in the field of process simulation. The framework will function as base when process simulation are performed both to measure the efficiency (time, cost) but also the energy consumption during construction.

\section{REFERENCES}

Baldwin, C. and Clark, K. (2000). Design rules: The power of modularity, MIT Press, Cambridge.

Flyvbjerg, B., Skamris Holm, M.K. and Buhl, S.L. (2004). "What Causes Cost Overrun in Transport Infrastructure projects?." Transport Review: A Transnational Trans disciplinary Journal., 24(1), 2-18.

Gibb, A.G.F. (2001). "Standardization and Pre-Assembly- Distinguishing Myth from Reality using Case Study Research." Construction Management and Economics., 19(3), 307-315.

Gosling, J. and Naim, M.M. (2009). "Engineer-to-order supply chain management: A literature review and research agenda." International Journal of Production Economics., 122(2), 741-754.

Green, S.D., Fernie, S. and Weller, S. (2005). "Making sense of supply chain management: a comparative study of aerospace and construction." Construction Management and Economics., 23(6), 579-593.

Haug, A., Ladeby, K. and Edwards. K. (2009). "From engineer-to-order to mass customization." Management Research News., 32(7), 633-644.

Hvam L., Mortensen, N. H. and Riis, J. (2008). Product Customization, Springer, Berlin.

Jansson, G. (2013). "Continuous development of house-buildning platform through experience feedback." Submitted for the Journal of Construction Innovation in October 2013.

Jensen, P., Larsson, J., Simonsson, P. and Olofsson, T. (2013). "Improving buildabuility with platforms and configurators." Proceedings of the $21^{\text {th }}$ International Group for Lean Construction, Fortaleza. 
Jensen, P., Olofsson, T. and Johnsson, H. (2012). "Configuration through the parameterization of building components." Automation in Construction., 23, $1-8$.

Jiao, J., Zhang, L. and Pokharel, S. (2003). "Process platform planning for mass customization." Proceedings of the $2^{\text {nd }}$ interdisciplinary world congress on mass customization and personalization, Munich, Germany.

Jongeling, R. and Olofsson, T. (2007). "A method for planning of work-flow by combined use of location-based scheduling and 4D CAD." Automation in Construction., 16(2), 189-198.

Larsson, J. Eriksson, P.E., Olofsson, T. and Simonsson, P. (2013). "Industrialized construction in the Swedish infrastructure sector: core elements and barriers." Construction Management and Economics, published online ahead of print.

Larsson, J. and Simonsson, P. (2012). "Decreasing complexity of the on-site construction process using prefabrication: a case study." Proceedings of the $20^{\text {th }}$ International Group for Lean Construction, San Diego.

Love, P.E.D., Lopez, R., Edwards, D.J. and Goth, Y.M. (2012). "Error begat errer: Design error analysis and prevention in social infrastructure projects." Accident Analysis \& Prevention., 48, 100-110.

Merriam, S.B. (1998) Qualitative Research and Case Study Applications in Education. San Francisco: Josey-Bass.

Meyer, M.H. and Lehnerd, A.P. (1997). The Power of Product Platforms; Building Value and Cost Leadership, The Free Press, New York.

Miller, T.D. and Elgård, P. (1998). "Defining modules, modularity and modularization." Proceedings of the $13^{\text {th }}$ IPS Research Seminar., Fuglsoe.

Minchin, E., Lewis, D. and McLeod, L. (2011). "Improving productivity on a troubled bridge project." Journal of Construction Engineering and Management., 137(5), 364-71.

Robertson, D. and Ulrich, K. (1998). "Planning for product platforms." Sloan Management Review., 39(4).

Styhre, A. and Gluch, P. (2010). "Managing knowledge in platforms: boundary objects and stocks and flows of knowledge." Construction Management and Economics, 28(6), 589-599. 